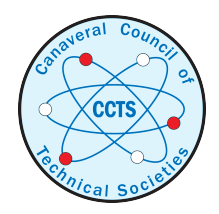

Mar 7th, 8:00 AM

\title{
A Program of Astronomy Research on the Moon and Its Logistics Implications
}

\author{
Raoul J. Freeman \\ The RAND Corporation \\ Roger C. Moore \\ The RAND Corporation \\ Gerhard F. Schilling \\ The RAND Corporation
}

Follow this and additional works at: https://commons.erau.edu/space-congress-proceedings

\section{Scholarly Commons Citation}

Freeman, Raoul J.; Moore, Roger C.; and Schilling, Gerhard F., "A Program of Astronomy Research on the Moon and Its Logistics Implications" (1966). The Space Congress ${ }^{\circledR}$ Proceedings. 2.

https://commons.erau.edu/space-congress-proceedings/proceedings-1966-3rd/session-2/2

This Event is brought to you for free and open access by the Conferences at Scholarly Commons. It has been accepted for inclusion in The Space Congress ${ }^{\circledR}$ Proceedings by an authorized administrator of Scholarly Commons. For more information, please contact commons@erau.edu.

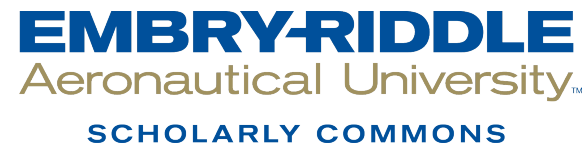


Raoul J. Freenan, ${ }^{*}$ Roger C. Moore, Gerhard F. Schilling The RAND Corporation, Santa Monica, California

\section{Abstract}

This study concerns itself with one aspect of possible post-Apollo space activity -- a program of astronomical research on the moon that culminates in the establishment of a lunar observatory. A mathematical model is utilized to analyze the logistics implications of conducting such an astronomical research program. The nature of the research equipment needed for the accomplishment of the program is outlined. Superposition of this research program upon a basic long-term lunar-base operations plan tentatively indicates that it could be feasible to conduct such a program of research during the 1970 's and 1980 's well within the constraints imposed by the logistics of presently planned spacecraft, boosters, and launching facilities. Although the best available numbers were used, the present study is viewed more as an exposition of a methodology than as the establishment of a conclusive result.

\section{Int roduction}

In a recent memorandum, 1 a mathematical model was developed to evaluate various aspects of the logistics supply support of space bases. This model plans a sequence of trips, their dates, and the composition of the cargoes needed on each trip to satisfy a series of supply requirements over a time spectrum imposed by the activities at the space base. The scheduling model can be used in two different modes: (a) as part of a control system for an actual space base, or (b) as a planning tool to aid in the design of a space base and the formulation of operations schedules.

In the earlier study, ${ }^{1}$ the model was illustrated in terms of a lunar base operation ${ }^{2}$ over a two-year period. In the present study, we superimpose the requirement to deliver scientific equipment necessary to conduct astronomical research and build an observatory on the moon upon the "regular" requirements of a permanent lunar base over an eight-year period. Using the model, 1 we are able to obtain some idea of the marginal stress put on the supply system by the astronomical research program, and obtain an indication of the logistic feasibility of the postulated research program.

The actual numerical results should not be interpreted as though they pertained to a proposed program of research. They serve to show the capability of the developed methodology to evaluate quantitatively the implications of superimposing demanding scientific requirements on an existing or planned supply-support system for space operations. The study itself illustrates how detalled logistics considerations

\section{* Now with General Electric Company, New} York City. could be introduced in the early planning phases of future space missions.

\section{Astronomical Requirements}

\section{General Considerations}

In order to use fully the inherent capabilities of the space-base supply-system model, 1 the scientific program to be evaluated must be developed in realistic terms. In the following discussion of astronomical research on the moon, even though we develop a detailed scenario, we wish to avoid two basic fallacies frequently present in research planning. The International Geophysical Year effort has taught us that it is difficult to plan a comprehensive research program solely on the basis of eminent advice and abstract ideas from the scientific community. Rather, one must find capable scientists willing to conduct specific research projects and build a program on and around such committed efforts. NASA's experience in planning its space program seems to reinforce this concept.

Planners also should avoid attempts to preplan in minute detail the "discoveries" to be made by a research program. What must be planned is the provision of basic equipment to enable the researcher to investigate the phenomena he finds intriguing. It is the researcher, not the planner, who is better able to design and use the terminal instrumentation that must be added to the basic equipment in order to permit a scientific experiment to be performed.

It should be kept in mind that observational astronomy is essentially the detection and analysis of electromagnetic radiation over the accessible range of frequencies. In general, a telescope is merely the basic equipment mentioned above. The individual experimenter adds his specific terminal instrument, be it a camera, photometer, or spectroscope, to the telescopic system at the specific focus that best meets his demands. Our discussion reduces itself, therefore, to (a) an examination of the basic equipment and facilities that could be erected advantageously on the moon in order to permit detection and amplification of electromagnetic radiation, and (b) guesses concerning the terminal instruments that experimenters -- on earth or on the moon -. may wish to have in operation on the moon at one time or another for one purpose or another.

The potential value of the moon as a site from which to perform astronomical research has received considerable attention in recent years. $3-7$ Discussions frequently have been imited to rather general considerations of the advantages and disadvantages of a lunar observatory compared to existing earth-based and potential earth-orbiting observatories. These 
arguments will not be repeated here. We grant without argument that there are astronomical studies that, for physical or economic reasons, (a) cannot be done from the moon, (b) can be done better from earth or from an earth-orbiting satellite than from the moon, or (c) cannot be foreseen at this time. We maintain, however, that basic equipment provided for Iunar astronomical research should allow for maximum freedom of choice in order for the actively interested experimenter to conduct, or have conducted, the astronomical studies he wishes to pursue.

Based on the above considerations, a scenario for a lunar astronomical research program has been developed to fulfill the input requirements of the space-base supply-system model. The scenario and the resulting program requirements are described in this section in terms of a possible sequence of events that are detailed sufficiently to serve this purpose. We believe that our sequential approach is the most realistic one possible at this time if one is to evaluate logistically the plans for a full-fledged lunar observatory a decade or two in the future.

Each sequential step contains a listing of support requirements that will satisfy the scientific objectives of the period. The astronomical requirements are divided into two categories: (a) basic equipment and facilities; (b) terminal scientific instrumentation.

The estimates of net weight do not include extensive packing material or complete provisions for protection against acceleration or vibration forces. They have sufficient validity to serve as input for a logistic model but should not be considered the actual weights of specific instruments.

The estimates of dimensions and volumes are schematically representative of rectangular boxes that would cover the required structural dimensions. Larger equipment is divided into the appropriate numbers of boxes needed to transport components for the complete structure. Depending on the amount of assembly visualized as taking place on the moon, larger boxes could -- In most but not all instances -- be further subdivided into smaller units.

It must be emphasized that the weight and volume data are strictly a first-order approximation. Elementary considerations will indicate that the nature and availability of such natural resources on the moon, as rocks, small craters, and the possibility of tunneling, can vary these basic data by large factors. Further, the ingenuity of local personnel and the possibility of laying out optical structures over wide terrain areas could significantly alter these numbers.

A sequential process of program planning can, however, be adapted to meet such changes in logistic requirements. It can also provide for such potential problems as the deterioration of optics due to meteoritic impact, the degradation of equipment from cosmic rays, and the erection of large structures in a vacuum.

\section{Pre-Apollo Period}

Before the first astronaut has landed on the moon, we can expect to witness the initial launchings of Orbiting Astronomical observatories (OAO) 8 and additional launchings of the already successful Orbiting Solar Observatories. ${ }^{9}$ Concurrently, Surveyor spacecraft ${ }^{10}$ will be soft-landed on the moon to conduct in situ experiments from the surface of that body. It would appear that exploratory astronomical observations could be readily performed from one of the planned Surveyors. Barring the resurrection of the recently completed Ranger program, 11 such observations would mark the beginning of a lunar astronomical research program.

Relatively simple, automatic instrumentation similar to that being developed for the first few orbiting astronomical observatories should be adaptable to the lunar surface environment. Even a very small telescope exploring the ultraviolet region of the spectrum could obtain new and useful data. It could survey the sky, using datacollection and-transmission principles developed for the $O A O$ project and could be employed as a simple transit instrument to obtain data on the libration of the moon. Such an instrument would be quite useful as a tool for examining the earth as a planet.

By merely being in operation, however, a small telescope might achieve its greatest usefulness as a site-survey instrument similar to those now employed on earth. Routine observations might, for example, determine through the twinkling of stars any remnant of lunar atmosphere, deterioration of optics from meteoritic impacts or other causes, and the general illumination characteristics of the location and of the "lunar sky."

\section{Apollo Flights}

Experience gained during the pre-Apollo period would be advantageous but is not mandatory to the conduct of astronomical experiments during early Apollo flights. Three activities can be distinguished:

(a) Astronomical observations by astronauts aboard Apollo spacecraft in test flights and in circumlunar orbits;

(b) Simple astronomical observations by astronauts during their periods of stay on the lunar surface;

(c) The activation, use, or servicing of semiautomatic astronomical equipment on the lunar surface by "visiting" astronauts.

A complete scenario of this period must further take into account the probable existence of unmanned solar and astronomical observatories and planetary spaceprobes. It must also allow for the state of progress of manned laboratories in orbit around the earth. An abundance of astronorical data should be available from these sources. 
Table 1 -- Astronomical Requirements During the Period of Early Apollo Flights

\begin{tabular}{lcc}
\hline \multicolumn{1}{c}{ Basic Equipment and Facilities } & Net Weight (1b) & Volume \\
\hline Semiautomatic Telescope, 6" (with finder telescope) & 50 & $50^{\prime \prime} \times 12^{\prime \prime} \times 12^{\prime \prime}$ \\
QUESTAR Telescope & 11 & $14^{\prime \prime} \times 7^{\prime \prime} \times 7^{\prime \prime}$ \\
Chronometers & 50 & $15^{\prime \prime} \times 15^{\prime \prime} \times 8^{\prime \prime}$ \\
Occultation Devices & 20 & $12^{\prime \prime} \times 12^{\prime \prime} \times 12^{\prime \prime}$ \\
\hline \multicolumn{1}{c}{ Terminal Scientific Instrumentation } & Net Weight (1b) & Volume \\
\hline Filters (box) & 5 & $12^{\prime \prime} \times 6^{\prime \prime} \times 6^{\prime \prime}$ \\
Camera & 5 & $12^{\prime \prime} \times 6^{\prime \prime} \times 6^{\prime \prime}$ \\
Astronomical Plates (boxes) & 25 & $5 \times\left[6^{\prime \prime} \times 6^{\prime \prime} \times 2^{\prime \prime}\right]$ \\
Spectroscope (attachment) & 10 \\
Recording Photometer & 15 \\
Data Storage Unit & 10
\end{tabular}

Examples of astronomical observations in the field of eclipse research have been discussed $i n$ detail in earlier studies. It has been shown 12 that astronauts' observations of eclipses, transits, and occultations from orbiting spacecraft wili provide data of value to astrophysics and geophysics. For observations made by astronauts from the surface of the moon, specific instrumentation and types of observations 13 have been suggested. These studies concentrate on relatively simple experiments, based on the assumption that early astronauts will have only limited experience and training as astronomical observers.

An important task for lunar astronauts may, therefore, be the use and activation of semiautomatic equipment that has been landed on the lunar surface before or concurrent with their arrival. A variety of important experiments could thus be conducted that fully automated Instruments could not perform as easily or economically. The modest astronomical requirements imposed on a logistics supply system during this period are listed in Table 1.

As has been emphasized before, ${ }^{13}$ we should not be under the illusion that early experiments need be complicated in order to make tremendous progress in many areas of astronomy. As of the time of this writing, for example, even such elementary problems as the rotation period of Mercury or the mass of the moon are unsolved.

\section{Apollo Follow-on}

During the $1970^{\prime} \mathrm{s}$, our scenario assumes that the use of the moon as an advantageous site for astronomical observations will begin to accelerate. Automatic equipment could perform sky surveys over a wide range of frequencies -- from the $\mathrm{X}$-ray and ultraviolet region of the electromagnetic spectrum to the far infrared. A small reflector of $6^{\prime \prime}$ to 12 " aperture could be employed as the basic equipment. Useful spectroscopic and photoelectric analyses of ultraviolet and infrared sources would be possible.

Even with such simple equipment, survey problems in positional astronomy, planetary astronomy, solar physics, and to a limited extent stellar and galactic astronomy, could be investigated. Specific investigations such as eclipse research could be conducted most fruitfully by the astronauts themselves. They would primarily handle raw-data acquisition with the equipment and instruments available.

In the pre-Apollo period, we limited ourselves to postulating rather moderate requirements for basic equipment and terminal instrumentation. During the Apollo followmon and subsequent phases, however, it would appear logical to assume that lunar astronomical activity should gradually begin to resemble, on a rather reduced scale, similar activity at an earth-based observatory. Table 2 is a listing of astronomical requirements based on this assumption.

Table 2 -- Astronomical Requirements During the Period of Apo1lo Follow-on Activities

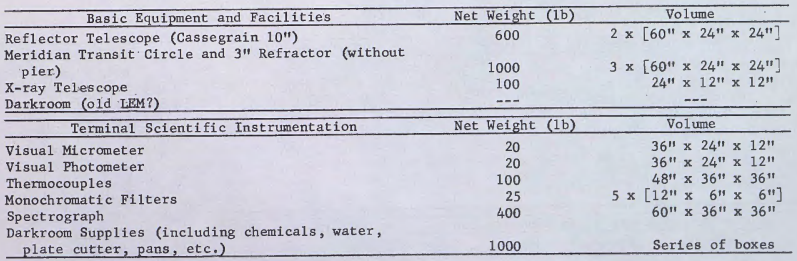


Table 3 -- Astronomical Requirements During the Period of Post-Apollo Activities

\begin{tabular}{|c|c|c|}
\hline Basic Equipment and Facilities & Net Weight (1b) & Volume \\
\hline $\begin{array}{l}\text { Schmidt Camera } \\
\text { Coronagraph } \\
\text { Radio Astronomy Antenna Net } \\
\text { Micro-Densitometer } \\
\text { Blink Comparator } \\
\text { Measuring Bngine } \\
\text { Linear Comparator } \\
\text { Machine Shop } \\
\end{array}$ & $\begin{array}{c}2000 \\
800 \\
\text { (miles of wire) } \\
1500 \\
500 \\
200 \\
500 \\
1000 \\
\end{array}$ & 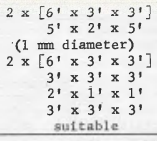 \\
\hline Terminal Scientific Instrumentation & Net Weight (1b) & Volume \\
\hline $\begin{array}{l}\text { Recording Photoelectric Photometer } \\
\text { Telescope Accessories } \\
\text { Image Converters } \\
\text { Polarimeter } \\
\text { Infrared Spectroneter }\end{array}$ & $\begin{array}{l}400 \\
600 \\
250 \\
150 \\
200\end{array}$ & $2 \times\left[\begin{array}{lllll}31 & x & 3 & x & 3 \\
3 & x & 3 & x & 3 \\
31 & x & 3 & x & 3 \\
3 & x & 1 & x & 2 \\
4 & x & 3 & x & 3\end{array}\right.$ \\
\hline
\end{tabular}

\section{Post-Apo110}

With the advent of permanent, or at least Indefinite, human occupancy of the moon, a new era of astronomy is postulated to begin. For our scenario, we sha11 assume that there is a gradual change from astronomical observations of a survey nature to the conduct of research projects. Initlally, the researcher probably remains on the earth, while a "night assistant" on the moon gathers the data. Activities benefit from correlated research projects involving the simultaneous use of orbiting solar and astronomical unmanned observatories, planetary probes, and manned orbiting laboratorles. It should be emphasized, however, that significant analysis, interpretation, and calibration of data depends most heavily on the conduct of correlated research at earth-based observatories.

Likely major equipment for the lunar astronomical faclity includes a reflecting telescope and a Schmidt camera. Further, 1 is rational to Include in our scenario, surface locomotion and exploration that permit the erection of ground antenna nets for use in radio astronomy. These nets are laid out where they will be shielded from earth-generated electromagnetic noise -- in a deep crater, perhaps, or in a location where the earth is on the moon's radio--optical horizon.

Certain activities, such as the tracking of earth sateliftes and space probes, constitute a challenge to maximum use of available instruments. Low-temperature circuits and solar power supplies play a determining role here. The rate of progress, however, depends also on the availability of natural lunar resources.

During this period, it can be expected that logistic and economic constraints, rather than scientific desirability alone, will determine when equipment of a specific size can be transported to the moon. Although Table 3 lists the estimated astronomical requirements for this period, no absolute time scale can realistically be given. As will be shown later, application of the space-base supply model can provide useful information for just such a problem situation.

\section{Lunar Observatory}

It can be assumed that the site of the principal lunar observatory will be on the side of the moon facing the earth. Except for radio telescopes, this location would not present a problem for astronomical research that could not be solved with suitable occultation equipment. Recall that the moon probably has no more than a very tenuous atmosphere and that the earth remains relatively fixed in the sky at all times for a given location on the moon.

As mentioned, the basic equipment provided, limited only by logistics, economics, and the ingenuity of the local personne1, will determine

Table 4 -- Typical Astronomical Requirements of a Lunar Observatory

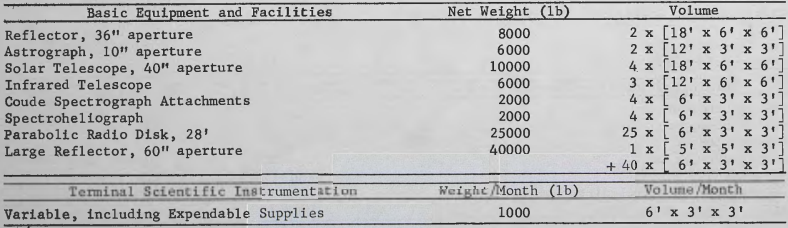


what research areas should be most actively pursued. Lightweight terminal instruments would, therefore, present no limit to the vast possibilities for astronomical research.

Experience with astronomical research on our planet to date, however, suggests that a limiting factor would be the number of astronomers interested in obtaining and analyzing data available from a lunar observatory. Finally, again from experience, the interests of the astronomer(s) in residence at the lunar observatory might determine what area of research would be stressed, be it galactic astroncmy, celestial dynamics, or a search for planets of nearby stars.

Table 4 represents an estimate of the logistic requirements of a lunar astronomical observatory capable of conducting a wide range of research projects. To obtain some indication as to whether these scientific desires are compatible with logistic realities, and if so, when we could expect to actually realize an astronomical observatory on the moon, we shall now turn to the mathematical model of supply support for answers.

\section{Space-Base Supply Mode1}

\section{Capabilities of the Model}

The mathematical model, which is more fully described in Ref. 1 , is a remarkably flexible tool for the planner. It can be programmed to simulate all principal steps in the logistic operation from supplier or manufacturer to the use of the supplies at the base. Once the requirements and restraints have been input, the computer can find and describe a feasible sched-. ule (if any) for getting the supplies to the base in the right sequence within the required times, with the specified vehicles, subject to such $1 \mathrm{im}-$ itations as weight and volume capacity of each vehicle, rate of supply, number of available launch pads, and maximum or minimum permissible interval between launches.

If desired, the requirements and restraints can be varied (for example, on the basis of what is learned in the first run) to reveal what effect on schedule these variations create. Likewise, the nature of the base's mission might be expanded or contracted on the basis of first results, and a new run made on the computer to show what constraints must be relaxed (or could be tightened), or what additional or reduced logistic effort is required as a result.

\section{Input Data}

Before using the mathematical model to analyze the logistic requirements of the lunar astronomy program described earlier, two steps had to be completed to prepare the necessary input data. First, the illustrative example of the study reported in Ref. 1 (namely, the requirements for a two-year period of operation of a manned lunar base) was extrapolated to an eightyear period, although the plan of operation calling for permanent occupancy by six men was retained. Secondly, the astronomical program requirements were translated into logistic data suitable for the model.

Al1 input data for the model are summarized in tabular form in the Appendix. The tabular entries are listings of base-supply modules and 1ogistics carriers. Weights and volumes are rounded to the nearest pound or cubic foot.

The basic unit element is the supply module -- to be thought of as a detachable or removable subassembly with a specific function or functions. It is identified by a number and a descriptive term indicative of its content. Each astronomical module is identified by a three-digit number followed by the letter A.

Each trip has been assigned a logistics carrier -- to be thought of as a spacecraft that contains modules as payload. A logistics carrier may itself serve a major module function such as providing shelter. To distinguish a carrier from a module, the identification number and volume of the former are listed in parantheses. Note that a carrier for a given trip provides volume capacity to be filled by supply modules.

Month zero is designated as the time of the first landing of base personnel. Bach tabular entry contains both the month of earliest possible delivery and the month of latest possible delivery with reference to month zero.

The first table in the Appendix (Table 8) consists, for the most part, of the base supplies planned for the original two-year period plus eight carriers required to deliver them. The modules and carriers in Table 9 are those needed for the additional six years of base operations. Table 10 is a list of astronomical modules, which contain astronomical equipment and supplies that must be delivered in order to conduct the astronomical program outlined earlier.

\section{Input Considerations}

The delivery of the regular supply modules 1isted in Tables 8 and 9 would support the lunar base for 96 months, given no unforeseen or emergency events. The latest possible time of delivery for each module is derived from an analysis of operations at the base, which indicates when certain modules will begin to be used according to the base's need for the supplies contained in that module. Bárliest possible time of delivery is a function of radiation and meteorite dangers and potential changes in the operations plans due to contingencies or discoveries or both.

Necessary shielding weights are based on the earlier study, 1 leading to a maximum desirable period of 24 months between earliest and latest possible delivery times for modules subject to radiation and meteoritic damage. A negative earliest possible delivery time implies that the module could be delivered prior to month zero, the time of the first landing of base personnel. 
It would be preferable to deliver the astronomical equipment and supplies in the same general order as discussed earlier. Arbitrary earliest and latest possible delivery times were attached to the astronomy modules (Table 10). However, the time intervals chosen were broad enough to ensure that the research could be undertaken without 1mperiling the build-up of regular operations and the safety of the base, the personnel, or the entire $\operatorname{logistic}$ supply system.

\section{Results From the Model}

\section{Computer Output}

With the input data detailed in the Appendix, two basically satisfactory computer runs will be discussed here. In the first, delivery of the regular supply modules and necessary carriers listed in Tables 8 and 9 was called for, and a satisfactory schedule was produced. The resulting trip-delivery schedule to the lunar base, permitting its operation for a perfod of eight years, 18 summarized in Table 5 .
In the second computer run, delivery of the same modules and carriers was called for, but now the astronomical modules of Table 10 were added. The results are summarized in terms of a logistic delivery schedule, in Table 6 . They represent the orderly logistic effort required to support the base plus an extensive lunar astronomical research program for eight years.

Analysis of the results of both runs indicated that a three-pad Saturn V launch complex with pad-turnaround times of one month can handle the required traffic. Payload weights on the 16 trips of the first run ranged from 22,720 to 26,080 pounds. The second run required 23 trips with payload weights ranging from 22,780 to 25,100 pounds. Assuming an average payload capacity of 25,000 pounds per launch for the Saturn V, slack on trips can be viewed as contingency allowance.

In the course of the study the volume of the astronomical equipment was found not to be a binding restraint on the launch system. About

Table 5 -- Results of First Computer Run (No Astronomical Modules)*

\begin{tabular}{ccccl}
\hline Trip & $\begin{array}{c}\text { Total } \\
\text { Weight } \\
(1 \mathrm{~b})\end{array}$ & $\begin{array}{c}\text { Earliest } \\
\text { Delivery } \\
\text { (month) }\end{array}$ & $\begin{array}{c}\text { Latest } \\
\text { Delivery } \\
\text { (month) }\end{array}$ & \multicolumn{1}{c}{ Modules and Carriers } \\
\hline 1 & 23,337 & -9 & 0 & $1 ;(6) ; 21 ; 25 ; 37$ \\
2 & 23,209 & -2 & 0 & $(13) ; 19 ; 20 ; 22 ; 27$ \\
3 & 22,720 & 0 & 3 & $(43) ; 55-58 ; 60-62 ; 125$ \\
4 & 22,820 & 7 & 7 & $2 ;(9) ; 14 ; 31 ; 34 ; 78 ; 79 ; 103-105 ; 126 ; 127$ \\
5 & 22,887 & 7 & 7 & $3 ;(10) ; 15 ; 17 ; 24 ; 26 ; 28 ; 30 ; 35 ; 38 ; 59 ; 80 ; 128$ \\
6 & 22,865 & 14 & 14 & $(7) ; 29 ; 32 ; 36 ; 39 ; 82$ \\
7 & 22,890 & 19 & 22 & $(12) ; 23 ; 33 ; 64 ; 131$ \\
8 & 23,255 & 21 & 22 & $4 ; 5 ;(11) ; 16 ; 18 ; 70 ; 81 ; 84$ \\
9 & 23,183 & 22 & 22 & $(8) ; 83 ; 109$ \\
10 & 22,970 & 22 & 23 & $(40) ; 63 ; 69 ; 85 ; 106 ; 108 ; 129 ; 130 ; 132$ \\
11 & 25,880 & 33 & 34 & $(45) ; 65 ; 71 ; 72 ; 86 ; 107 ; 110 ; 133-135$ \\
12 & 25,730 & 43 & 48 & $(44) ; 73 ; 87-91 ; 111-113 ; 136-138$ \\
13 & 26,080 & 51 & 59 & $(42) ; 74 ; 92 ; 93 ; 114-117 ; 139 ; 140$ \\
14 & 25,040 & 71 & 71 & $(46) ; 75 ; 94 ; 95 ; 98-101 ; 118 ; 119 ; 141-146$ \\
15 & 24,950 & 74 & 76 & $(41) ; 96 ; 97 ; 120-124$ \\
16 & 24,980 & 77 & 77 & $(47) ; 66-68 ; 76 ; 77 ; 102 ; 147$ \\
\hline
\end{tabular}

* Contents of the modules are identified in Table 8 of the Appendix. 
Table 6 -- Results of Second Computer Run (A11 Modules)*

\begin{tabular}{|c|c|c|c|c|}
\hline Trip & $\begin{array}{l}\text { Total } \\
\text { Weight } \\
\text { (1b) }\end{array}$ & $\begin{array}{l}\text { Earliest } \\
\text { Delivery } \\
\text { (month) }\end{array}$ & $\begin{array}{l}\text { Latest } \\
\text { Delivery } \\
\text { (month) }\end{array}$ & Modules and Carriers \\
\hline 1 & 22,859 & 0 & 0 & $\begin{array}{l}\text { (9); } 19 ; 20 ; 25 ; 27 ; 56 ; 78 ; 148 \mathrm{~A} ; 150 \mathrm{~A}-156 \mathrm{~A} ; 158 \mathrm{~A}-161 \mathrm{~A} ; 163 \mathrm{~A} \text {; } \\
164 \mathrm{~A} ; 166 \mathrm{~A} ; 168 \mathrm{~A}\end{array}$ \\
\hline 2 & 22,847 & 0 & 0 & $1 ;(6) ; 21 ; 31 ; 34 ; 169 \mathrm{~A} ; 292 \mathrm{~A} ; 293 \mathrm{~A}$ \\
\hline 3 & 22,840 & 0 & 2 & $(12) ; 22 ; 37 ; 64 ; 149 \mathrm{~A} ; 157 \mathrm{~A} ; 165 \mathrm{~A}$ \\
\hline 4 & 22,780 & 2 & 3 & $(51) ; 55 ; 57-61 ; 65 ; 127 ; 162 \mathrm{~A} ; 167 \mathrm{~A}$ \\
\hline 5 & 23,787 & 7 & 7 & $4 ; 5 ;(10) ; 14 ; 15 ; 17 ; 24 ; 26 ; 28 ; 30 ; 38 ; 128$ \\
\hline 6 & 23,651 & 11 & 14 & $3 ;(7) ; 32 ; 35 ; 36 ; 39 ; 81$ \\
\hline 7 & 23,507 & 15 & 17 & $(8) ; 29 ; 33 ; 70$ \\
\hline 8 & 23,880 & 18 & 19 & $(45) ; 69 ; 79 ; 103-106 ; 131$ \\
\hline 9 & 23,620 & 19 & 19 & $(40) ; 62 ; 80 ; 82 ; 83 ; 107 ; 108 ; 125 ; 126 ; 129 ; 130$ \\
\hline 10 & 24,565 & 22 & 22 & $(11) ; 18 ; 23 ; 109$ \\
\hline 11 & 23,670 & 22 & 22 & $2 ;(13) ; 16 ; 84 ; 85 ; 170 \mathrm{~A}-173 \mathrm{~A}$ \\
\hline 12 & 24,700 & 40 & 40 & $(47) ; 63 ; 71 ; 86 ; 110 ; 132 ; 133 ; 135 ; 181 \mathrm{~A}-189 \mathrm{~A}$ \\
\hline 13 & 24,600 & 44 & 48 & $(44) ; 87 ; 88 ; 111-113 ; 134 ; 136 ; 192 \mathrm{~A} ; 213 \mathrm{~A} ; 214 \mathrm{~A} ; 263 \mathrm{~A} ; 267 \mathrm{~A}$ \\
\hline 14 & 24,530 & 44 & 49 & $\begin{array}{l}(53) ; 72 ; 114 ; 115 ; 138 ; 190 \mathrm{~A} ; 191 \mathrm{~A} ; 193 \mathrm{~A}-195 \mathrm{~A} ; 212 \mathrm{~A} ; 261 \mathrm{~A} ; \\
26 \mathrm{AA} ; 273 \mathrm{~A}\end{array}$ \\
\hline 15 & 24,910 & 54 & 55 & $(42) ; 73 ; 74 ; 89-93 ; 95 ; 116 ; 117 ; 137 ; 140 ; 262 \mathrm{~A}$ \\
\hline 16 & 24,740 & 59 & 60 & $(52) ; 66-68 ; 75 ; 178 \mathrm{~A} ; 179 \mathrm{~A}$ \\
\hline 17 & 24,850 & 60 & 60 & $(48) ; 174 \mathrm{~A}-177 \mathrm{~A} ; 180 \mathrm{~A} ; 222 \mathrm{~A} ; 255 \mathrm{~A}-260 \mathrm{~A} ; 265 \mathrm{~A} ; 271 \mathrm{~A}$ \\
\hline 18 & 24,820 & 60 & 71 & $(46) ; 94 ; 229 \mathrm{~A}-254 \mathrm{~A} ; 266 \mathrm{~A}$ \\
\hline 19 & 24,800 & 64 & 66 & (49); $139 ; 141-144 ; 196 \mathrm{~A} ; 215 \mathrm{~A} ; 220 \mathrm{~A} ; 225 \mathrm{~A} ; 227 \mathrm{~A} ; 228 \mathrm{~A} ; 294 \mathrm{~A}$ \\
\hline 20 & 25,100 & 64 & 73 & $(41) ; 268 \mathrm{~A}-270 \mathrm{~A} ; 274 \mathrm{~A}-291 \mathrm{~A}$ \\
\hline 21 & 24,900 & 67 & 73 & (54); $96 ; 118-122 ; 226 \mathrm{~A}$ \\
\hline 22 & 25,010 & 74 & 80 & $(43) ; 102 ; 197 \mathrm{~A}-211 \mathrm{~A} ; 216 \mathrm{~A}-219 \mathrm{~A} ; 221 \mathrm{~A} ; 223 \mathrm{~A} ; 224 \mathrm{~A}$ \\
\hline 23 & 24,700 & 77 & 77 & $(50) ; 76 ; 77 ; 97-101 ; 123 ; 124 ; 145-147 ; 272 \mathrm{~A}$ \\
\hline
\end{tabular}

* Contents of the modules are identified in tables 8,9 , and 10 of the Appendix.

6000 pounds of "other," nonspecified scientific equipment was, therefore, delivered during the first 22 months of operation of the base.

Table 7 is a listing of arrival times -- at the lunar base -- of some of the major astronomical equipment. For equipment that has been split into several parts, the delivery time given is that of the last part needed to make the equipment complete. Note however, that while partial assembly can commence earlier, operation will realistically start only some time after assembly has been completed.

\section{Discussion}

It was mentioned in the Introduction that the mathematical model can be used in two different modes. The numerical data from the two basic computer runs described here must be considered as planning estimates. Before using the mode1 in an operating real-time mode many additional considerations would have to enter. We shall give one simple example.

Table 7 -- Arrival Times of Selected Major Items of Astronomical Equipment

\begin{tabular}{lc}
\hline \multicolumn{1}{c}{ Equipment } & $\begin{array}{c}\text { Month of } \\
\text { Latest }\end{array}$ \\
\hline Delivery
\end{tabular}


A matching of the launch intervals against pad avallability on a three-pad launch complex with a pad-turnaround time of one month would indicate the "ample" feasibility of both runs" launch intervals. But given the number of launch pads actually avallable, the arrival rate of space vehicles at the pads, the turnaround time of each pad, etc., one could assess whether a planned launch complex can handle the launch schedule on the basis of the intervals indicated by the model's results. One might wish to have one pad ready at all times to deal with emergencies. Should the launch intervals derived by the model not be compatible with the facllities at the launch complex, the parameters of the model could be adjusted to derive a different set of launch intervals that would stili adequately support the operations at the base in space. Computation would continue until it was established that there is no compatible schedule of launches for the planned complex, or until a suitable schedule is found.

For the present runs, neither launch failures nor emergencies in space were considered. Work is underway, however, to develop a mode1 that can better consider these and other stochastic aspects of actual space operations.

Considerable research remains before it is possible to determine with accuracy the logistic implications of creating a lunar astronomical research program. All weight estimates would have to be refined, because of their sensitivity in relation to the model. In addition, alternate plans should be analyzed and the conjectural aspects of space operations investigated. On the basis of the two computer runs described, however, it would appear feasible to deliver to the moon al1 the equipment and instrumentation listed in the Appendix within seven years after the start of a long-term manned lunar-base operation. It further would appear that the cost of the astronomy program is seven additional trips during the eight-year period of operation considered here. The launch intervals imvolved also seem compatible with a program of resupply of the essentials needed to keep the base in operation and with personnel rotation requirements.

Recognize, however, that we have been considering the delivery of astronomical nodules in relative isolation from other scientific equipment, and have examined neither the assembly, restraints imposed by the lunar environnent nor the number of persons avallable for construction.

\section{Conclusions}

Consider first the example used here to fllustrate the capabilities of the mathematical model of the supply support of space operations. of the equipment called for by the sciences to be placed on the moon for some time to come, that called for by astronomy is probably the bulkiest. One may argue the scientific merits of such an endeavor, but a priori, we were not able to estimate, even remotely, whether a 60 -inch telescope on the moon would be a logistically and economically realistic task for this century or for the next.
Though interesting and useful, the numerical results presented in this paper are of secondary significance at this time. The primary importance is the demonstration of a technique that can generate meaningful logistic statements from such diverse input parameters as weight and volume of equipment, capacities of launch vehicles and spacecraft, number of available launch pads, scientific mission objectives, allowable times of unattended storage of expendable goods, and many others. Furthermore, any input can be examined in parametric fashion in order to determine the sensitivity of the whole system to it.

Consider now the implications of having this tool available to the space-mission planner. Hardware and supply requirements, as well as scientific and technical objectives, can be scaled up or down; operations schedules can be extended in time or shortened; mission alternatives can be compared quantitatively, including the comparison of such missions as accomplishing a specific scientific objective by means of a lunar base vs. an orbiting laboratory, by means of manned operations vs. unmanned spacecraft.

We readily conclude that use of the spacebase supply model can greatly assist in the integrated mission planning and comparative evaluation of space programs.

Acknowledgments. We wish to acknowledge the helpful suggestions of R.B.S. Brooks, D. C. Gogerty, G. W. Graves, and G. E. Kocher while this work was in progress. The research reported here was sponsored by the United States Air Force under Project RAND, Contract No. AF $49(638)-1700$, monitored by the Directorate of Operational Requírements and Development Plans, Deputy Chief of Staff, Research and Development, Hq USAF. Views or conclusions contained in this paper should not be interpreted as representing the official opinion or policy of the United States Air Force. 


\section{Appendix}

Table 8

Base Supply Modules and Logistics Carriers for Initial Two-Year Period of Operations

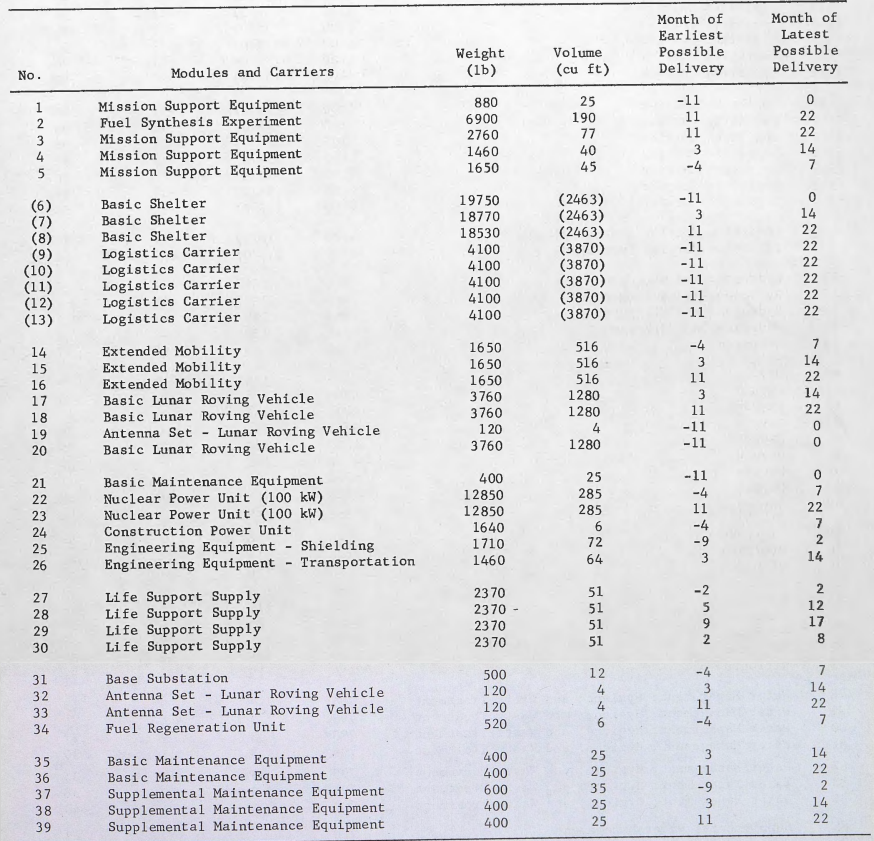


Table 9

Base Supp1y Modules and Logistics Carriers for Added Six-Year Period of Operations

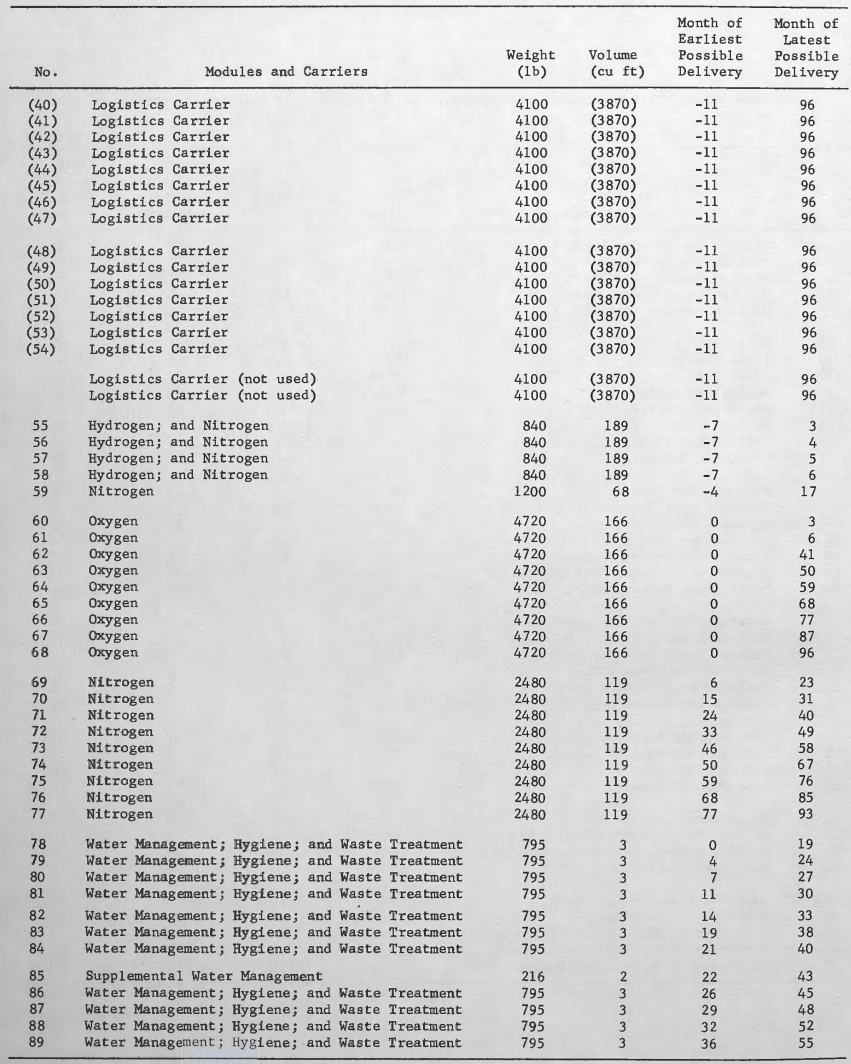




\begin{tabular}{|c|c|c|c|c|c|}
\hline No. & Modules and Carriers & $\begin{array}{l}\text { Weight } \\
\text { (1b) }\end{array}$ & $\begin{array}{l}\text { Volume } \\
\text { (cu ft) }\end{array}$ & $\begin{array}{l}\text { Month of } \\
\text { Earliest } \\
\text { Possible } \\
\text { Delivery }\end{array}$ & $\begin{array}{l}\text { Month of } \\
\text { Latest } \\
\text { Possible } \\
\text { Delivery }\end{array}$ \\
\hline $\begin{array}{l}90 \\
91 \\
92 \\
93\end{array}$ & $\begin{array}{l}\text { Water Management; Hygiene; and Waste Treatment } \\
\text { Water Management; Hygiene; and Waste Treatment } \\
\text { Water Management; Hygiene; and Waste Treatment } \\
\text { Water Management; Hygiene; and Waste Treatment }\end{array}$ & $\begin{array}{l}795 \\
795 \\
795 \\
795\end{array}$ & $\begin{array}{l}3 \\
3 \\
3 \\
3\end{array}$ & $\begin{array}{l}39 \\
43 \\
46 \\
49\end{array}$ & $\begin{array}{l}59 \\
62 \\
65 \\
68\end{array}$ \\
\hline $\begin{array}{l}94 \\
95 \\
96 \\
97 \\
98\end{array}$ & $\begin{array}{l}\text { Supplemental Water Management } \\
\text { Water Management; Hygiene; and Waste Treatment } \\
\text { Water Management; Hygiene; and Waste Treatment } \\
\text { Water Management; Hygiene; and Waste Treatment } \\
\text { Supplementa1 Hygiene }\end{array}$ & $\begin{array}{l}216 \\
795 \\
795 \\
795 \\
140\end{array}$ & $\begin{array}{l}2 \\
3 \\
3 \\
3 \\
1\end{array}$ & $\begin{array}{l}51 \\
54 \\
57 \\
61 \\
62\end{array}$ & $\begin{array}{l}71 \\
73 \\
76 \\
80 \\
83\end{array}$ \\
\hline $\begin{array}{r}99 \\
100 \\
101 \\
102\end{array}$ & $\begin{array}{l}\text { Water Management; Hygiene; and Waste Treatment } \\
\text { Water Management; Hygiene; and Waste Treatment } \\
\text { Water Management; Hygiene; and Waste Treatment } \\
\text { Supplemental Water Management; and } \\
\text { Supplemental Waste Treatment }\end{array}$ & $\begin{array}{l}795 \\
795 \\
795 \\
655\end{array}$ & $\begin{array}{l}3 \\
3 \\
3\end{array}$ & $\begin{array}{l}65 \\
68 \\
71 \\
74\end{array}$ & $\begin{array}{l}84 \\
87 \\
90 \\
94\end{array}$ \\
\hline $\begin{array}{l}103 \\
104 \\
105 \\
106 \\
107 \\
108\end{array}$ & $\begin{array}{l}\text { Food } \\
\text { Food } \\
\text { Food } \\
\text { Food } \\
\text { Food } \\
\text { Food }\end{array}$ & $\begin{array}{l}3845 \\
3845 \\
3845 \\
3845 \\
3845 \\
3845\end{array}$ & $\begin{array}{l}28 \\
28 \\
28 \\
28 \\
28 \\
28\end{array}$ & $\begin{array}{r}0 \\
4 \\
12 \\
11 \\
15 \\
18\end{array}$ & $\begin{array}{l}19 \\
24 \\
27 \\
31 \\
34 \\
38\end{array}$ \\
\hline $\begin{array}{l}109 \\
110 \\
111 \\
112 \\
113 \\
114\end{array}$ & $\begin{array}{l}\text { Food } \\
\text { Food } \\
\text { Food } \\
\text { Food } \\
\text { Food } \\
\text { Food }\end{array}$ & $\begin{array}{l}3845 \\
3845 \\
3845 \\
3845 \\
3845 \\
3845\end{array}$ & $\begin{array}{l}28 \\
28 \\
28 \\
28 \\
28 \\
28\end{array}$ & $\begin{array}{l}22 \\
25 \\
29 \\
32 \\
36 \\
39\end{array}$ & $\begin{array}{l}42 \\
45 \\
49 \\
52 \\
56 \\
59\end{array}$ \\
\hline $\begin{array}{l}115 \\
116 \\
117 \\
118 \\
119\end{array}$ & $\begin{array}{l}\text { Food } \\
\text { Food } \\
\text { Food } \\
\text { Food } \\
\text { Food }\end{array}$ & $\begin{array}{l}3845 \\
3845 \\
3845 \\
3845 \\
3845\end{array}$ & $\begin{array}{l}28 \\
28 \\
28 \\
28 \\
28\end{array}$ & $\begin{array}{l}43 \\
46 \\
50 \\
53 \\
57\end{array}$ & $\begin{array}{l}63 \\
66 \\
70 \\
73 \\
77\end{array}$ \\
\hline $\begin{array}{l}120 \\
121 \\
122 \\
123 \\
124\end{array}$ & $\begin{array}{l}\text { Food } \\
\text { Food } \\
\text { Food } \\
\text { Food } \\
\text { Food }\end{array}$ & $\begin{array}{l}3845 \\
3845 \\
3845 \\
3845 \\
3845\end{array}$ & $\begin{array}{l}28 \\
28 \\
28 \\
28 \\
28\end{array}$ & $\begin{array}{l}60 \\
64 \\
67 \\
71 \\
74\end{array}$ & $\begin{array}{l}80 \\
84 \\
87 \\
91 \\
94\end{array}$ \\
\hline $\begin{array}{l}125 \\
126 \\
127 \\
128 \\
129 \\
130\end{array}$ & $\begin{array}{l}\text { Clothing } \\
\text { Clothing } \\
\text { Lithium Hydroxide } \\
\text { Clothing; and Lithium Hydroxide } \\
\text { Clothing; and Lithium Hydroxide } \\
\text { Clothing; and Lithium Hydroxide }\end{array}$ & $\begin{array}{r}1101 \\
1101 \\
148 \\
1249 \\
1249 \\
1249\end{array}$ & $\begin{array}{l}8 \\
8 \\
1 \\
8 \\
8 \\
8\end{array}$ & $\begin{array}{r}0 \\
4 \\
2 \\
7 \\
12 \\
16\end{array}$ & $\begin{array}{l}19 \\
24 \\
21 \\
27 \\
31 \\
35\end{array}$ \\
\hline $\begin{array}{l}131 \\
132 \\
133 \\
134 \\
135 \\
136\end{array}$ & $\begin{array}{l}\text { Clothing } \\
\text { Clothing; and Lithium Hydroxide } \\
\text { Clothing; and Lithium Hydroxide } \\
\text { Clothing } \\
\text { Clothing; and Lithium Hydroxide } \\
\text { Clothing; and Lithium Hydroxide }\end{array}$ & $\begin{array}{l}1101 \\
1249 \\
1249 \\
1101 \\
1249 \\
1249\end{array}$ & $\begin{array}{l}8 \\
8 \\
8 \\
8 \\
8 \\
8\end{array}$ & $\begin{array}{l}18 \\
22 \\
26 \\
29 \\
32 \\
36\end{array}$ & $\begin{array}{l}38 \\
42 \\
45 \\
49 \\
52 \\
56\end{array}$ \\
\hline $\begin{array}{l}137 \\
138 \\
139 \\
140 \\
141 \\
142 \\
143\end{array}$ & $\begin{array}{l}\text { Clothing } \\
\text { Clothing; and Lithium Hydroxide } \\
\text { Clothing; and Lithium Hydroxide } \\
\text { Clothing; and Lithium Hydroxide } \\
\text { Clothing } \\
\text { Clothing; and Lithium Hydroxide } \\
\text { Clothing; and Lithium Hydroxide }\end{array}$ & $\begin{array}{l}1101 \\
1249 \\
1249 \\
1249 \\
1101 \\
1249 \\
1249\end{array}$ & $\begin{array}{l}8 \\
8 \\
8 \\
8 \\
8 \\
8 \\
8\end{array}$ & $\begin{array}{l}39 \\
43 \\
46 \\
51 \\
53 \\
57 \\
60\end{array}$ & $\begin{array}{l}59 \\
62 \\
66 \\
70 \\
73 \\
77 \\
80\end{array}$ \\
\hline $\begin{array}{l}144 \\
145 \\
146 \\
147\end{array}$ & $\begin{array}{l}\text { Clothing } \\
\text { Clothing; and Lithium Hydroxide } \\
\text { Clothing; and Lithium Hydroxide } \\
\text { Clothing }\end{array}$ & $\begin{array}{l}1101 \\
1249 \\
1249 \\
1101\end{array}$ & $\begin{array}{l}8 \\
8 \\
8 \\
8\end{array}$ & $\begin{array}{l}64 \\
67 \\
71 \\
74\end{array}$ & $\begin{array}{l}84 \\
86 \\
91 \\
94\end{array}$ \\
\hline
\end{tabular}


Astronomical Modules Containing Scientific Equipment, Instrumentation, and Supplies

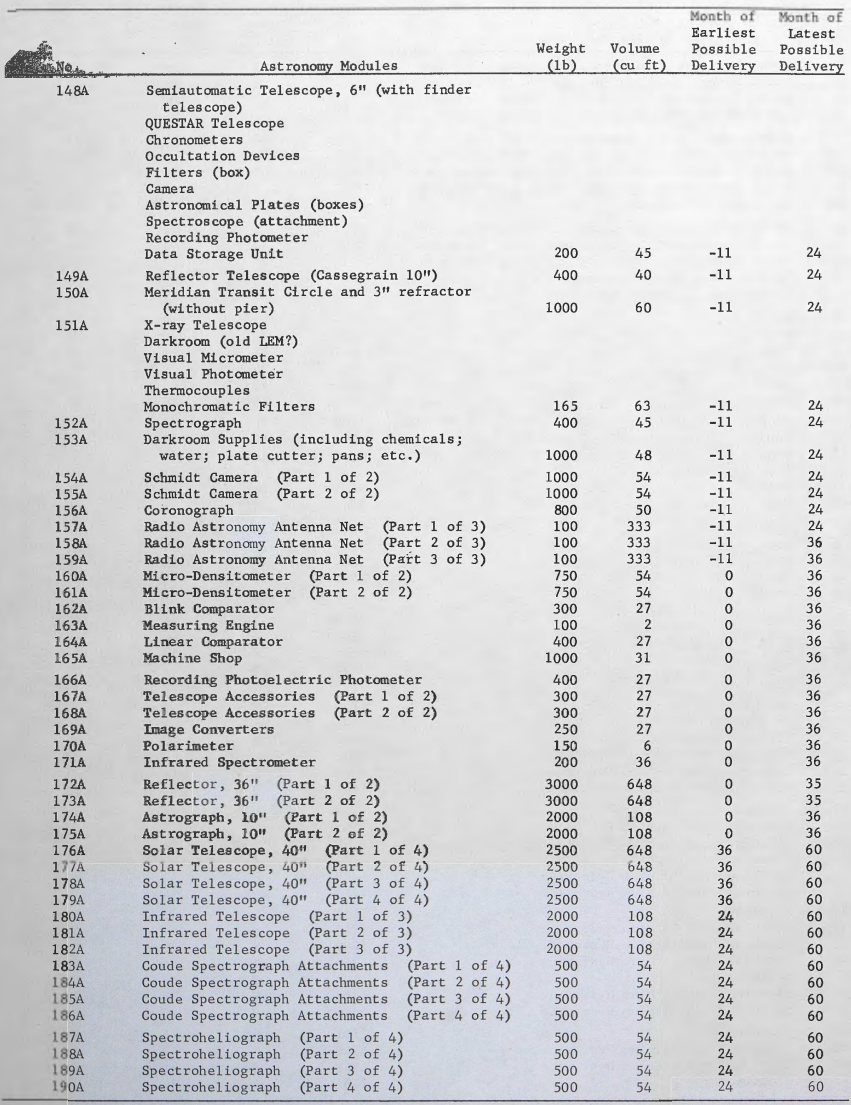




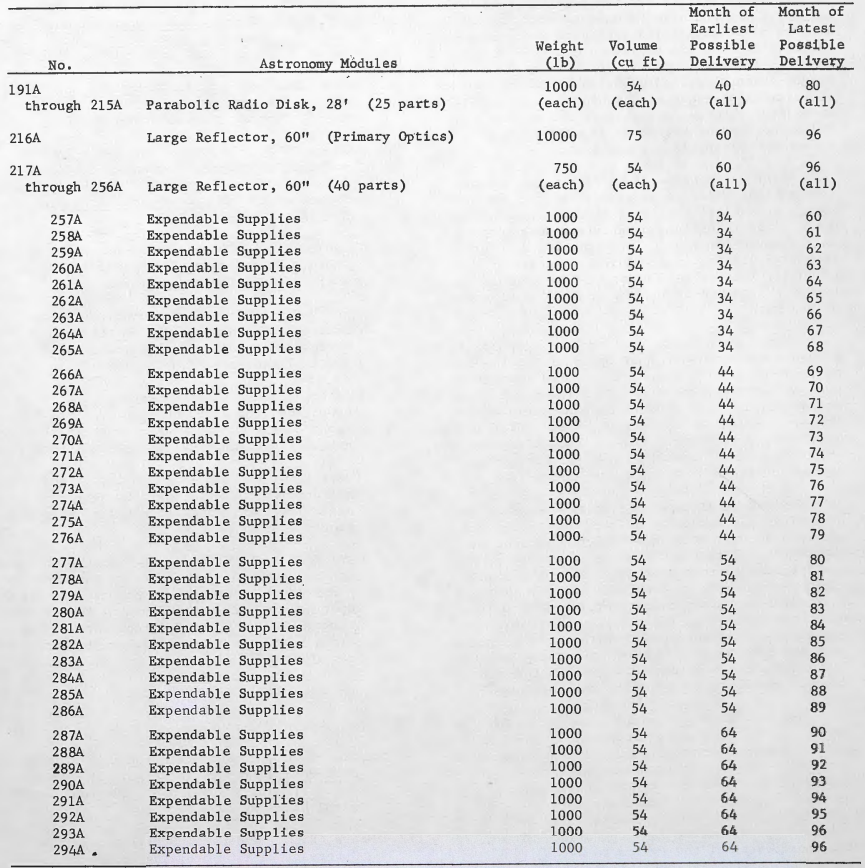


In an earlier study, a mathematical model was described that can be used to evaluate various aspects of the logistics supply support of space operations. The present study utilizes this model to investigate the implications of superimposing a set of demanding scientific requirements on an existing space base support plan. An illustrative example demonstrates the flexibility and usefulness of the model as a tool for integrated space-mission planning.

First, a scenario is developed for a lunar astronomical research program in sufficient detall to fulfill the input requirements of the model. The resulting scientific requirements are described in terms of the equipment and instrumentation desired in a temporal sequence of gradually increasing demands that culminates in the establishment of an astronomical observatory on the moon.

These requirements then are superimposed on a supply report system that provides for the establishment and operation of a manned lunar base over an eight-year period. Detailed input parameters consider such aspects as capacities of launch vehicles and spacecraft, number of launch pads and pad turnaround times, scientific mission obfectives, and allowable times for unattended storage of expendable goods, to name a few.

The numerical results from two computer runs determined the necessary delivery schedules and provided an indication of the logistic cost of the postulated mission. For the specific astronomical example investigated, the results indicated that a lunar astronomical research program that culminates in the construction of a lunarbased observatory is logistically feasible. Further, such an observatory with sizable equipment could be established -- without any unrealistic logistic requirements -- within the next decades rather than during the next century.

However, these numerical results are of secondary significance at this time. The primaxy importance of the study is the demonstration of a technique that permits the quantitative comparison of the logistical aspects of alternative space wissions where many interrelated input paraneters can be examined in parametric fashion to determine the sensitivity of the system to each. Possible future applications include the quantitative analysis of such alternatives as reaching a specific technical objective by means of a lunar base or with an orbiting laboratory, by means of manned operations or with unmanned spacecraft.
1. Freeman, R. J., D. C. Gogerty, G. W. Graves, and R.B.S. Brooks, A Mathematical Model of Supply Support for Space Operations, RM-4520-PR, The RAND Corporation, April 1965.

2. Boeing Company, Initial Concept of Lunar Exploration Systems for Apollo, Vols. 1-5, NASA CR-35, Contract NASw-792, March 1964.

3. Malina, F. J., "Report of the Lunar International Laboratory Discussion Panel, XVth International Astronautical Congress, Warsaw, September 1964," Astronautica Acta, Vol, 11, No. 2, pp. $123-13 \overline{2,1965 .}$

4. Gorgolewski, S., "Lunar Radio Astronomy Observatory," Presented at XVIth International Astronautical Congress, Athens, 1965.

5. Krat, V. A., "On Solar Observations at an International Observatory on the Moon," Presented at XVIth International Astronautical Congress, Athens, 1965.

6. Mojzherin, V. M., V. B. Nikonov, V. K. Prokofiev, and N. S. Chernih,"Optical Telescope on the Moon," Presented at XVIth International Astronautical Congress, Athens, 1965.

7. Stehling, K. R., and I. M. Levitt, "Lunar Astronomical Observatory," Presented at XVIth International Astronautical Congress, Athens, 1965.

8. "1965 NASA Authorization," Hearings before the Subcormittee on Space Sciences and Applications of the Committee on Science and Astronautics, United States House of Representatives, Eighty-Eighth Congress, Second Session, February--March 1964, No. 1, Part 3, pp. 1692-1698.

9. Ibid., pp. 1681-1692.

10. Ibid., Pp. 1800-1806.

11. Moore, R. C., A Suggestion for Extension of the NASA Ranger Project in Support of Manned Space Flight, RM-4353-NASA, The RAND Corporation, December 1964.

12. Moore, R. C., and G. F. Schilling, Eclipse Observations from Orbiting Spacecraft, RM-4557-PR, The RAND Corporation, May 1965.

13. Schilling, G. F., A Suggested Program of Eclipse Observations from the Moon, RM-4249-NASA, The RAND Corporation, August 1964. 